\title{
Utilizando mapas conceitual, de cenário e navegacional no apoio ao processo de desenvolvimento de objetos de aprendizagem
}

\section{Rogério Avellar C. Cordeiro, Clevi E. Rapkiewicz, Maria Cristina Canela , Angélica Freitas dos Santos, Eduardo Coelho Carneiro Universidade Estadual do Norte Fluminense Darcy Ribeiro}

ravellar@gmail.com, \{clevi,mccanela,afsantos\}@uenf.br,duducarneiro@yahoo.com.br

Resumo. $O$ desenvolvimento de objetos de aprendizagem (OA), quando não feito pelos próprios usuários, pode ser feito por equipes multidisciplinares, integrando pessoas de área técnica (computação), da área de domínio, pedagógica, entre outras. $O$ processo de comunicação entre os integrantes da equipe bem como a própria evolução do desenvolvimento do OA ao longo do ciclo de vida costuma ser registrada de alguma forma. Entre as formas utilizadas encontra-se o conjunto de fases e documentos propostos no âmbito do projeto RIVED (MEC). Este artigo discute as limitações do processo proposto e propõe algumas inovações ao mesmo, incorporando mapas (conceitual, de cenários e navegacional), tornando o processo geral o suficiente para ser utilizado em outros âmbitos de desenvolvimento de OAs. Propõe, ainda, ummodelo ágil e colaborativo de forma a facilitar a integração entre as equipes e tornar o processo de desenvolvimento mais efetivo.

Palavras-chave: Objetos de aprendizagem, mapa de conceitos, mapa de cenários, mapa navegacional e metodologia interdisciplinar. 


\section{Introdução}

Atualmente é quase lugar-comum afirmar a necessidade de integração de equipes técnicas com equipes da área de domínio, buscando trabalho interdisciplinar. Embora, esta questão não seja mais uma novidade na produção de software, alguns grupos ainda trabalham de forma convencional no desenvolvimento de produto de software nos quais os especialistas da área de domínio são considerados usuários que repassam as necessidades para a equipe técnica. Por outro lado, SILVA E FERNANDES (2006) ressaltam que na formação de professores, por exemplo, deve haver a preocupação com ações pedagógicas condizentes com o desenvolvimento tecnológico da sociedade de uma maneira que os futuros professores não precisam apenas saber utilizar recursos tecnológicos que tenham sido preparados e desenvolvidos por outros, mas, sim, saberem fazer seus próprios materiais e, inclusive, saberem como usar as novas tecnologias numa perspectiva de mediação pedagógica.

Uma alternativa possível é a participação dos usuários no processo de desenvolvimento não de forma restrita nas atividades para elicitação dos requisitos, com os profissionais de informática recebendo especificações dos usuários, mas com integração dos usuários durante todo o ciclo de desenvolvimento, gerando equipes multidisciplinares. Esta alternativa porém tem a limitação das dificuldades existentes para integração de profissionais oriundos de áreas distintas. Estas dificuldades encontram-se sobretudo nos aspectos de comunicação.

A integração completa de equipes só é obtida quando existem "alfabetos" em que os integrantes de ambas tenham conhecimento, necessitando então de instrumentos para que a comunicação seja efetiva, principalmente quando estas equipes estão voltadas sempre a abordagens específicas, seja do conteúdo a ser abordado (equipe de domínio) e a implementação deste propriamente dita via algoritmos e programação (equipe técnica). Essa necessidade é premente em diferentes contextos de desenvolvimento de software educativo, incluindo casos de políticas públicas cujos objetivos incluem o incentivo ao trabalho interdisciplinar. Esse é o caso, por exemplo, do projeto RIVED - Rede Interativa Virtual de Educação, projeto mantido através da parceria entre a Secretaria de Educação Básica (SEB) e da Secretaria de Educação a Distância (SEED) do Ministério da Educação (RIVED, 2006). Uma das ações desse projeto é a produção de conteúdos digitais através da Fábrica Virtual, que estende para universidades o papel de desenvolver Objetos de Aprendizagem (OA). Em cada universidade que atua na Fábrica, os OAs são desenvolvidos seguindo um conjunto de etapas, apresentadas na seção 2 , nas quais são gerados documentos que buscam facilitar o desenvolvimento do processo como um todo. Esses documentos servem de registro de produtos intermediários antes da existência efetiva do OA e servem também como documentos de comunicação entre as equipes.

No entanto, os processos propostos pelo RIVED apresentam alguns pontos críticos, já apontados por AMARAL et al (2006), como por exemplo, a não explicitação “de momentos de 2 V. 5 № 1, Julho, 2007 
refinamento, onde o grupo multidisciplinar possa discutir e interagir de modo a aprimorar as especificações do OA" (p.374). Os mesmos autores destacam, pertinentemente, que o modelo proposto pelo RIVED "também não possui uma fase de validação junto aos usuários finais (estudantes e professores) antes da publicação do OA para testar sua efetividade" (p. 374).

Apesar das considerações de AMARAL et al (2006) serem bastante pertinentes, necessitam de algumas complementações, as quais são os focos deste artigo: i) o instrumento de comunicação entre as equipes (roteiro) possuir algumas limitações; ii) a inserção de refinamentos sucessivos mantém a filosofia dos modelos clássicos de desenvolvimento de software.

Este artigo propõe a incorporação de mapas no processo. Para tanto, está dividido em 4 seções além desta introdução. Na próxima seção, é apresentado o modelo proposto pelo RIVED para desenvolvimento dos OAs, já com algumas considerações quanto as limitações citadas acima. Na seção seguinte, são descritos brevemente modelos de desenvolvimento de software, com base em PRESSMAN (2006), com o objetivo de situar o leitor no contexto da discussão proposta. Na seção 4 são feitas algumas propostas de desenvolvimento e, finalmente, na seção 5, são apresentadas algumas considerações finais.

\section{Modelo RIVED}

Conforme citado, atualmente, no contexto do Fábrica Virtual, o desenvolvimento dos OAs é realizado através de um trabalho interdisciplinar, ou seja, ocorrem interações entre uma equipe técnica e uma equipe de domínio (também conhecida por equipe pedagógica). A forma como essas interações são conduzidas interferirá diretamente na qualidade, foco e principalmente no prazo (deadline) do material a ser produzido.

O modelo do processo de desenvolvimento de objetos sugerido pelo RIVED segue as mesmas diretrizes empregadas pelo modelo em cascata (ciclo de vida clássico), modelo no qual é sugerida uma abordagem sistemática e linear. O desenvolvimento deste modelo requer que ambas as equipes possuam bom entendimento dos requisitos, tendo estes bem definidos, pois este modelo não prevê "ciclos de realimentação" (apesar de suportá-los). Desde a pesquisa levantada pela equipe de domínio até o desenvolvimento do próprio objeto, o problema/objetivo deverá estar muito bem compreendido bem como organizado. Este aspecto já foi levantado, conforme já citado, por AMARAL et al (2006). 

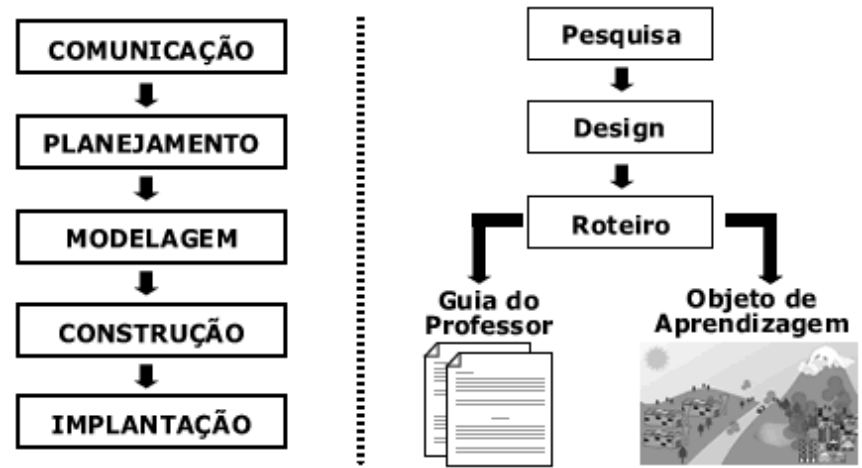

Figura 1. Comparativo Modelo em Cascata / Modelo RIVED

$\mathrm{O}$ desenvolvimento de $\mathrm{OA}$ enquanto produto precisa de três fases: planejamento (modelagem), desenvolvimento e validação. Esta última etapa, apesar de não ser formalmente sugerida no modelo RIVED, é seguida por muitas equipes do Fábrica Virtual e teve sua incorporação ao processo discutida por AMARAL et al (2006). Esta etapa é fortemente recomendada, pelo alto nível de maturidade e abstração que é aderida ao OA, principalmente quando novos incrementos (releases) são disponibilizadas (a ver posteriori).

$\mathrm{Na}$ fase de modelagem são produzidos dois documentos pela equipe pedagógica:

- Design Pedagógico: documento que descreve em linhas gerais as idéias dos autores para um determinado módulo. Ele traz os objetivos educacionais, o tema central e as atividades/estratégias de aprendizagem para o aluno. Este documento é um planejamento de como ensinar certo conteúdo utilizando as potencialidades do computador.

- Roteiro: O roteiro é a descrição detalhada de todas as telas que irão compor o objeto. A elaboração do roteiro ajuda a visualizar o produto final e pode reduzir frustrações e o tempo de produção. No entanto, é um documento estritamente linear que dificulta tanto a visão do todo por parte da equipe pedagógica quanto a visão da estrutura de navegação do OA por parte da equipe técnica.

A partir da confecção do roteiro, ocorre a produção concomitante do OA e do Guia do Professor (GP), ou seja, enquanto a equipe técnica se empenha em desenvolver o OA baseado no roteiro apresentado pela equipe de domínio, a equipe de domínio constrói o GP que tem por objetivo sugerir uma condução da atividade em sala, além de ter o propósito de enriquecer a formação do professor (NASCIMENTO e MORGADO, 2004).

Percebe-se que para o modelo do RIVED, todas as fases devem estar bem definidas para que o processo de produção possa continuar, ou seja, as fases posteriores só poderão ser iniciadas quando as fases anteriores a ela já estiverem sido finalizadas (uma lista de dependência). O problema é que raramente os projetos seguem o fluxo seqüencial que o modelo propõe (PRESSMAN, 2006). Nem sempre todos os requisitos estão expostos a fim de que a equipe de domínio possa detalhar completamente no roteiro. A fim de exemplificação, novas adaptações no OA como alfabetização visual, navegabilidade e acessibilidade só são perceptíveis quando pelo menos um objeto modelo (release zero) é criado e apresentado a 
equipe de domínio. Portanto, alguns equívocos são cometidos durante o processo de desenvolvimento de um OA, fazendo-se necessário, portanto, a retomada em fases anteriores e consertando o que fora produzido equivocadamente.

Há necessidade de se adequar novas ferramentas que auxiliem o modelo apresentado pelo RIVED, visando aprimorar a colaboração entre as equipes em questão e sanar as deficiências apontadas. $\mathrm{O}$ emprego de processos ágeis e interativos no desenvolvimento do $\mathrm{OA}$ pode permitir que alterações sejam feitas tanto nas fases iniciais como nas fases finais, mesmo que a detecção para estas mudanças seja detectada na própria (e principalmente) validação. $\mathrm{O}$ uso de recursos gráficos juntamente ao roteiro, também auxiliaria no desenvolvimento destes objetos no que se diz respeito à navegabilidade entre as telas, visto que a estrutura de navegação não deve seguir um padrão seqüencial e linear, limitando as potencialidades de exploração do OA pelos usuários finais.

\section{Modelos de Processo}

Há muitas situações em que os requisitos iniciais do software são razoavelmente bem definidos, mas o escopo global do esforço de desenvolvimento elimina um processo puramente linear (PRESSMAN, 2006). Além disso, não temos uma previsibilidade de como um sistema computacional irá se comportar com o tempo, ou seja, existem situações nos quais não há como prever quais requisitos serão persistidos ou quais serão modificados. Às vezes o emprego de pequenas amostras (releases) lançadas antes mesmo do fim definitivo do software em si, seja para fazer uma breve validação do objeto, refinar requisitos ou até mesmo já fazer a adaptações no objeto em si, são alternativas encontradas para que o desenvolvimento seja mais rápido (ágil) e consistente. A análise, projeto, construção e validação não são tão previsíveis (do ponto de vista do planejamento) como gostaríamos, por isso um processo ágil deve ser adaptável.

\subsection{Modelo Cascata}

Este modelo parte do princípio de que o prosseguimento das fases só é possível de ser realizado quando a fase em questão for considerada como finalizada por completo. Avançando por fases de forma seqüencial e linear, este modelo não prevê ciclos (apesar de suportá-los), fazendo com que adequar novas adaptações no modelo do desenvolvimento dos OAs não seja tão trivial. Esta não trivialidade se dá pela raridade em que todos os requisitos estejam bem definidos, de tal forma que se identifiquem quais serão ou não persistidos. E conforme comentado anteriormente, também sabemos que os requisitos dos usuários são passiveis de mudança a todo instante e, portanto, a aplicabilidade deste modelo no desenvolvimento de OAs, torna o processo mais lento, tendo que ser realizadas várias modificações entre o roteiro e software para que ao final da produção não se tenham produtos equivocados da realidade proposta. 


\subsection{Modelos Incrementais}

Os modelos incrementais combinam elementos do modelo em cascata aplicado de maneira interativa. A equipe de domínio às vezes não tem uma noção adequada de como cobrar um determinado conteúdo dos alunos, enquanto por outro lado eles possuem uma noção geral de como organizar as idéias. Existem também casos emergenciais de se produzir um OA com um conjunto limitado de funcionalidade, onde futuramente refinamentos feitos sobre o OA/requisitos serão aplicados no modelo.

Em ambos os casos, o modelo incremental é sugerido por servir de avaliador tanto para as equipes, visto que a partir de um pequeno modelo já criado (release zero), a equipe de domínio pode efetivamente visualizar/testar os requisitos por ela levantada, enquanto que a equipe técnica também pode detectar algum equívoco sobre o roteiro elaborado (navegabilidade inconsistente, falta de informações na tela, etc).

\subsection{Modelos Evolutivos}

O software, como todo sistema complexo, evolui com o passar do tempo (GILB, 1998). Assim como requisitos alteram-se durante o tempo, o software deve se adequar a estes requisitos, buscando atender a novas necessidades dos clientes (alunos) bem como aperfeiçoar o objetivo a ser alcançado. Até mesmo antes de um objeto ser considerado finalizado, os requisitos já foram modificados, fazendo-se necessário, portanto, adaptá-lo aos novos requisitos e atualização dos outros materiais também já desenvolvidos (DP, GP e roteiro). Os modelos evolutivos são interativos, caracterizando-se de forma a permitir a equipe técnica desenvolver releases mais completas (maduras) do OA.

\subsection{Modelos Ágeis}

O primeiro motivo pelo qual deve se aplicar um desenvolvimento ágil, é que o ambiente moderno de negócios que cria sistemas baseados em computador e produtos de softwares é apressado e sempre mutável (PRESSMAN, 2006). Intui-se então que deve haver uma comunicação constante entre equipes, a fim de que sempre possa adaptar os novos requisitos no objeto em questão.

Cinco são os tópicos-chaves do desenvolvimento ágil: nível maior de abstração e maturidade empregado ao OA, onde o objeto possa atingir mais de um propósito para o qual ele foi planejado (ex: utilizando sub-partes do mesmo - acoplamento fraco) em diferentes situações; a constante comunicação inter-equipes, construindo assim um meio colaborativo onde são levantadas novas informações capazes de fornecer valores de negócio aos alunos; cada equipe conhece bem a área em que são capazes de manter o controle sobre o trabalho; ênfase sobre uma entrega rápida (curto prazo) de um modelo funcional; e o reconhecimento que as adaptações 
feitas no produto apresentam oportunidades valiosas para o aluno e para o amadurecimento do software.

Filosofias como estas já são aplicadas hoje pelos Modelos Ágeis de processo, tais como: XP (Extreme Programming), Scrum, Crystal, etc.

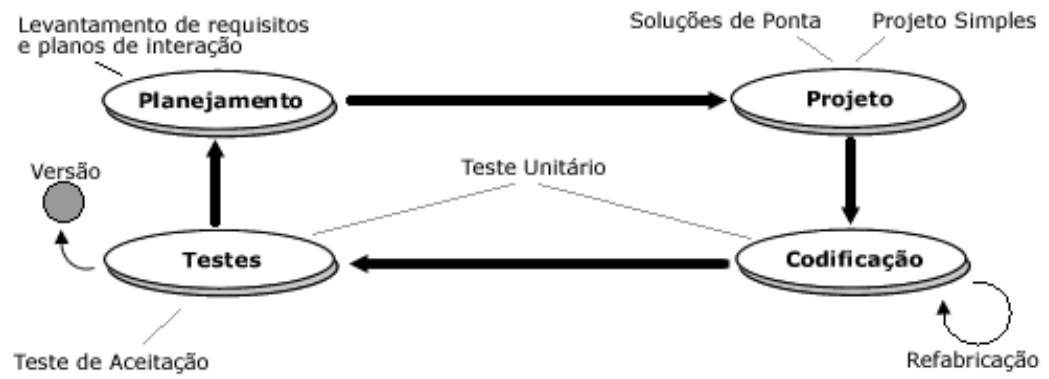

Figura 2. O Processo Extreme Programming (XP)

Tomando como exemplo o desenvolvimento de OAs, obtém-se releases (versões) em menores intervalos de tempo, onde o meio colaborativo existente entre as equipes técnica e domínio, permita principalmente acomodar novas adaptações em todo o OA (GP, DP, OA, roteiro), com maior facilidade e mais abrangência (abstrato).

\section{Uma proposta de metodologia}

Seja qual for a situação em que um processo interdisciplinar seja bem conduzido, equívocos, melhorias, modificações são levantadas e classificadas antes do processo ser materializado em si. Mais do que a detecção destes aspectos, este processo torna os indivíduos envolvidos mais contextualizados no que se está desenvolvendo, permitindo-os a sugerir e até mesmo assumir certas atividades que antes não foram previsto no escopo ${ }^{1}$. A aplicação de reuniões com ambas equipes, explorando os brainstorms, associado com uso de material gráfico e visual como os Mapas (como apresentado a seguir), storyboards, quadro de prioridades, diagramas, etc, são fundamentais por traduzirem de forma eficiente uma realidade abstrata em documentos concretos. Os modelos visuais são aplicados no desenvolvimento de software desde os primeiros paradigmas, visando principalmente mapear as informações a serem utilizadas nos sistemas em diagramas². "Os principais diagramas são usados em todas as fases, mudando apenas a sua visão" (Melo, 2004). Aos integrantes das equipes permite-se participar mais ativamente de todo o processo e garantir que não existirão surpresas quanto à compreensão de requisitos.

\footnotetext{
${ }^{1}$ Conhecida na Engenharia de Software como Atividades guarda-chuva (Umbrella Activities)

2 Ex: Diagrama de Objetos, Diagrama de Caso de Uso, Diagrama de Entirade Relacionamento (DER), Diagrama de Fluxo de Dados (DFD), etc. 
Pelo motivo de adotar metodologias sistemáticas e lineares, que não prevêem amortizações dos impactos dos erros, os processos de desenvolvimento que aplicam este modelo cometem vários equívocos, que é o caso do processo de desenvolvimento de um OA sobre os moldes do RIVED conforme apresentado anteriormente. O problema é que eles só são perceptíveis quando o objeto em si é considerado como finalizado pela equipe técnica, após ler o roteiro (que é a única fonte de pesquisa) encaminhado pela equipe de domínio. $\mathrm{O}$ trabalho se torna mais árduo quando se necessita de uma adaptação a ser feita nos materiais já produzidos. Este fenômeno acontece por se tratar de uma forma de desenvolvimento puramente linear, seqüencial e hierárquica, no qual o nível de dependência entre os documentos produzidos cresce concomitantemente com a produção dos materiais.
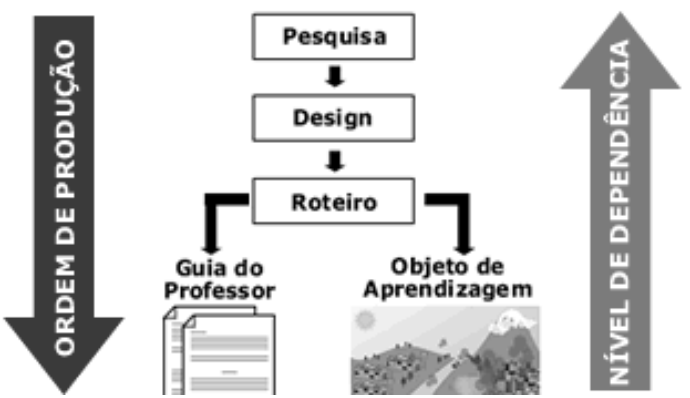

Figura 3. Comparativo de Produção/Dependência

Portanto, algumas sugestões de melhoramentos ao modelo do RIVED são sugeridas, tal como a criação de Mapas de Conceito (MCo), Mapa de Cenários (MCe), Mapa Navegacional (MN) e Modelo de Processo Colaborativo.

\subsection{Panorama gráfico do Design Pedagógico usando Mapa de Conceito e Mapa de}

\section{Cenários}

Para deixar mais claro o DP, atualmente de uso apenas pela equipe pedagógica, propõe-se o desenvolvimento de dois mapas que auxiliarão na abordagem dos conteúdos propostos. O primeiro mapa gerado é o Mapa de Conceito, cuja finalidade é levantar os conteúdos (conceitos) que devem ser abrangidos pelo OA. No âmbito do RIVED é o MEC quem delega a uma determinada equipe a responsabilidade de abordar tais temas a partir de um mapeamento. Mas a forma de relacionar os conteúdos entre si é atribuição das equipes. Na prática, em qualquer projeto de desenvolvimento de OAs haverá a delimitação do escopo, em termos de conteúdo, do que será abordado: a primeira, etapa, então, é delimitar o que será abordado no OA bem como a forma como as partes do conteúdo se relacionam entre si. Por exemplo, na figura 4 abaixo, é apresentado um mapa de conceitos para um objeto versando sobre a distribuição de água no planeta e alguns aspectos da química relacionados com a água. 


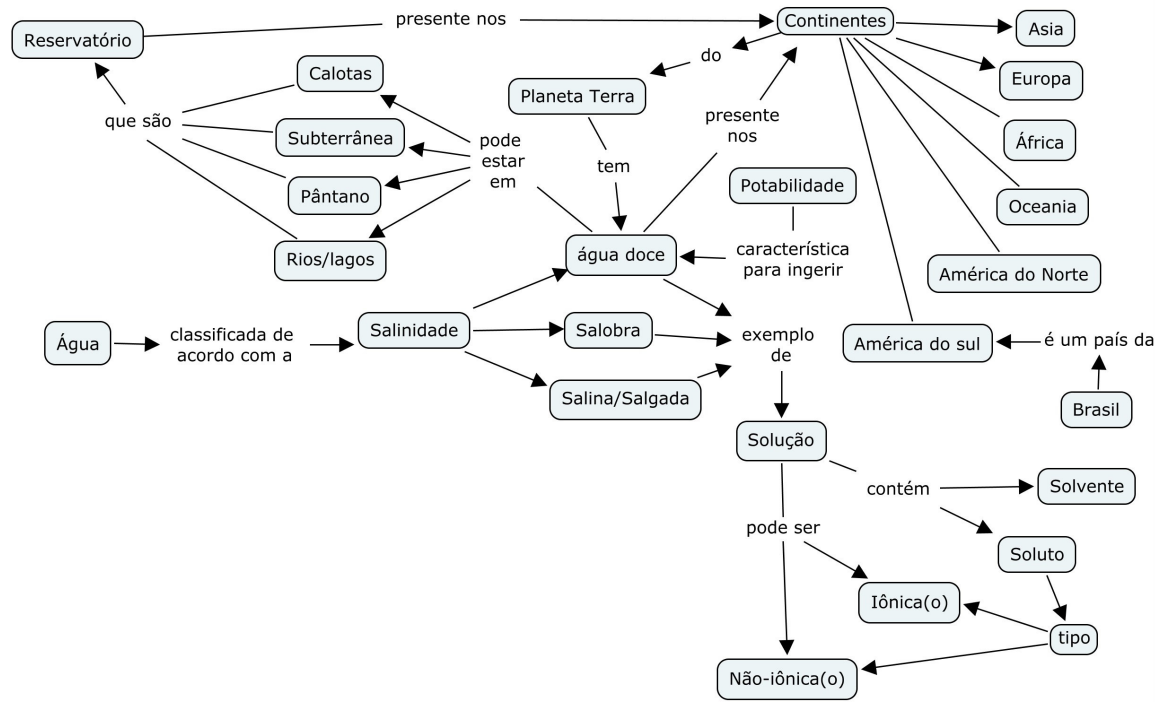

Figura 4. Mapa de conceitos do objeto Distribuição

A próxima etapa é definir como tais conceitos serão trabalhados no âmbito do OA em construção. Visando a contextualização do conteúdo, relacionando o mesmo o mais possível com a realidade dos alunos, propõe-se a delimitação de cenários que serão utilizados para desenvolver os conceitos propostos através de um Mapa de Cenários. Nos nós são indicados os cenários e nas arestas quais conceitos ou conteúdos serão trabalhados.

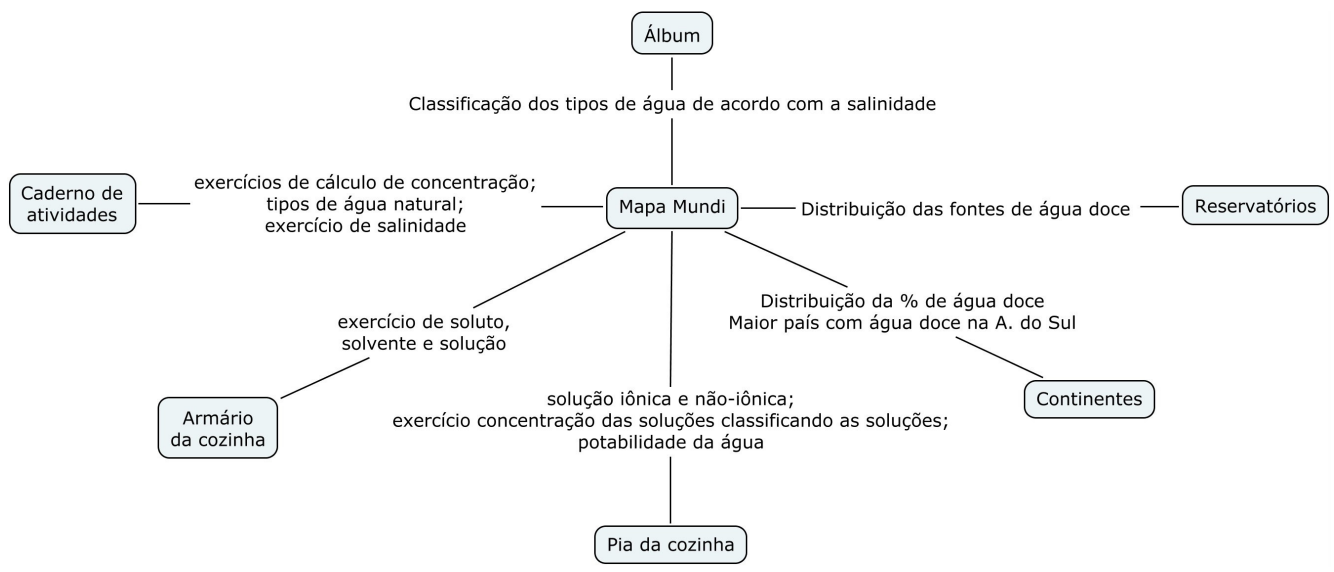

Figura 5. Mapa de cenários do objeto Distribuição

Através do Mapa de Cenários mostrado pode-se observar o objeto como um todo. O objeto está centrado no cenário de um Planeta (Terra) e o usuário poderá explorar vários subcenários - continentes, lbum de fotos, reservatórios de água, caderno de anotações, armário da cozinha, bancada da cozinha e pia da cozinha - e aprender vários conceitos abordados dentro da temática da distribuição da água - tipos de água; conceitos de soluto, solvente e solução; definição de água doce, salobra e salgada; potabilidade da água; soluções iônicas e não-iônicas; tipos de água e exemplos. Esses conceitos estavam definidos no Mapa de Conceitos. O Mapa 
de Cenários permite tanto à equipe técnica quanto à equipe de domínio uma visão macro de todo o cenário no quais os diversos contextos de aprendizagem serão utilizados pelos alunos através da manipulação do OA. Cada nó do mapa indica um cenário (contexto) no qual um determinado conteúdo (mostrado nas arestas de ligação entre os nós) será trabalhado.

\subsection{Uma visão gráfica do Roteiro usando Mapa Navegacional}

Quando a equipe técnica recebe o roteiro confeccionado pela equipe domínio, a equipe técnica deve passar os requisitos escritos no papel para as funcionalidades do computador, ou seja, implementar de fato aquilo que fora planejado ideologicamente no computador, através de algoritmos, programação, etc. Muitas vezes o próprio programador (não lhe cabendo a este dever) detecta algumas ambigüidades consistidas no roteiro no que se refere a navegabilidade entre as telas dos objetos. Como se trata apenas de uma folha de papel e normalmente a navegabilidade entre as telas não segue uma sequiência linear, o próprio integrante da equipe de domínio se confunde ao referenciar as ações dos botões existentes na tela.

Como um complemento ao roteiro, a proposta é criar um Mapa Navegacional (MN), que auxilie tanto o implementador (equipe técnica) a compreender o direcionamento que deve ser dado nas telas, como os idealizadores (equipe de domínio) que poderá através dele conferir se a navegabilidade está consistente com a idéia do objeto ou está falhando em alguma tela.

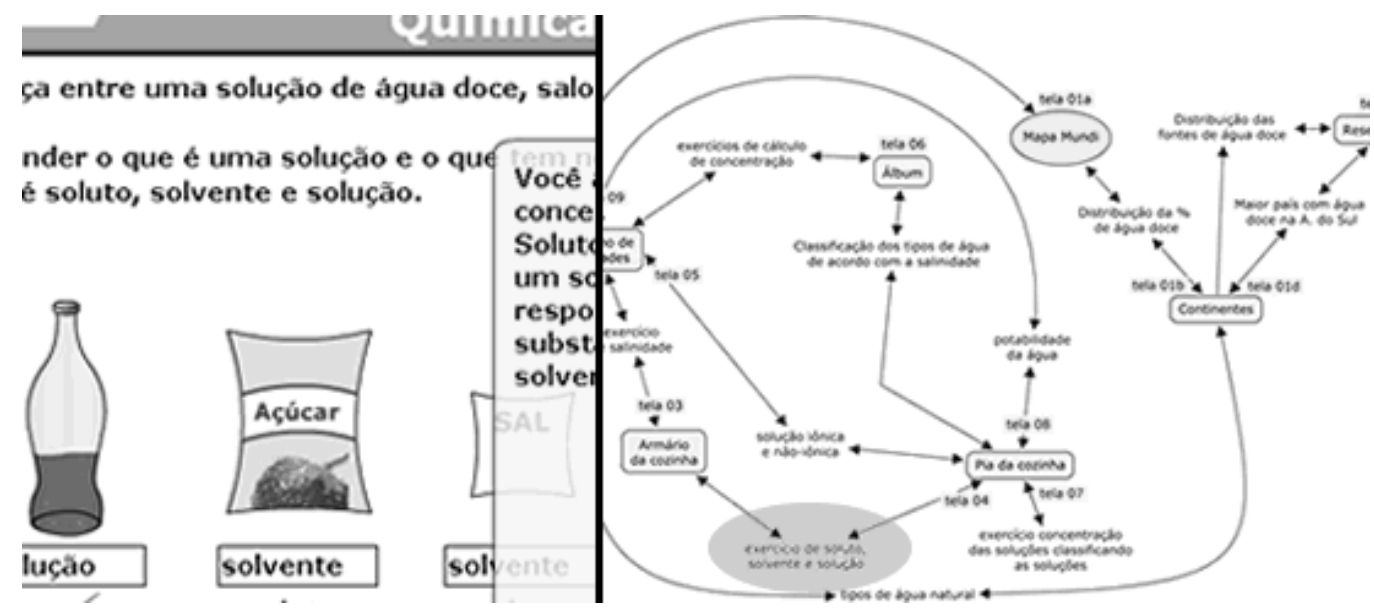

Figura 6. Fragmento do OA Distribuição de Água à esquerda e destaque desta mesma tela no Mapa Navegacional

Com funcionamento semelhante a um Diagrama de Fluxo, o Mapa Navegacional demonstra para ambas as equipes como o aluno navegará entre as telas. As direções das setas demonstram como será feito o trajeto "origem-destino" e dentro das setas estão os conteúdos que serão abordados. Dentro dos quadrantes estarão as numerações das telas (na aba superior ao quadrante) e o título da animação corrente. Desta forma fica de melhor compreensão pra todos 
"qual tela encaminha/retorna a qual tela", permitindo identificar ainda os botões que terão essa ação (ex: se todos estão presentes na tela, se algum botão não está tomando a ação correta, etc).

A título de exemplo, o roteiro condizente ao objeto da Figura 6 não encontrou nenhuma ambigüidade quanto à navegabilidade. Mesmo que as releases não tivessem todas as telas incorporadas no objeto, quando elas foram inseridas bastou apenas adicionar o código (script) sobre os botões que as referenciassem. Dois fatos são relevantes na Figura 6: 1) A navegabilidade (através dos botões) apresentada na parte inferior das telas; e 2) No MN, quando as telas prosseguem pelo mesmo contexto, a numeração permanece a mesma, acrescentando somente letras para hierarquização.

\subsection{Modelo de Processo Colaborativo}

Tomando como exemplo a metodologia do XP (Extreme Programming), a comunicação constante deve estar presente em todas as fases do processo de desenvolvimento de um OA. Percebemos o quanto isto é necessário para acomodar novas adaptações ao projeto, filtrar equívocos oriundos pela falta de uma release para validação e o tempo demandado para a fabricação de um objeto.

O trabalho multidisciplinar sendo aplicado em todas as fases com a filosofia de desenvolvimento ágil, principalmente, reduz o tempo gasto com o desenvolvimento de um objeto, pois enquanto uma release está sendo analisada pela equipe de domínio, outras releases continuam sendo lançadas como melhoramento das anteriores. Depois de analisada cada release lançada pela equipe técnica, a equipe de domínio pode ou não sugerir adaptações nos GP e DP passando uma nova versão de roteiro a equipe técnica para que possa aplicar sobre o objeto em si. Vale ressaltar que para cada entrega de uma release (recomenda-se a partir da segunda) a necessidade de se fazer uma breve reunião com o intuito de discutir os requisitos que foram bem ou mal atendidos, colocando em discussão também as novas versões dos roteiros, DP, GP e Mapa Navegacional. Desta forma a equipe técnica pode intervir (dar sugestões) nas áreas que antes era somente de conhecimento da equipe de domínio e vice-versa. 


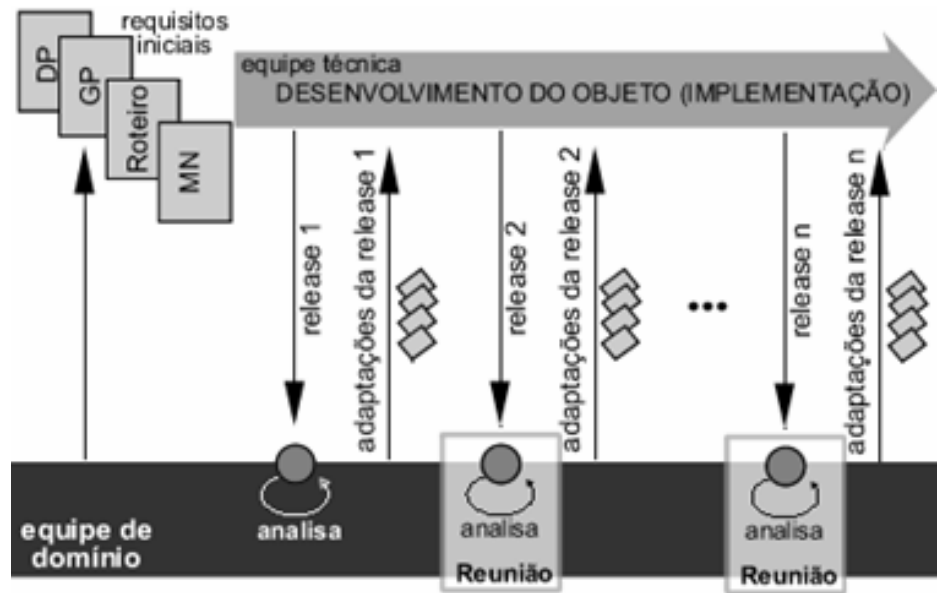

\section{Figura 7. Esquema do Modelo de Processo Colaborativo}

É importante observar também que o deadline do objeto foi cumprido sem que fosse preciso efetuar alguma modificação na agenda do projeto. Desta forma, o objeto além de ter os prazos cumpridos, o objeto se tornou mais maduro, mais robusto, sofrendo refinamento até hoje (principalmente após testes realizados com os alunos) das ferramentas nele aplicado.

Como pode ser visualizado na figura abaixo (Figura 8), as releases a priori buscavam atingir as funcionalidades essenciais do objeto, tais como disposição de figuras na tela, animação básica, apresentação dos textos e navegação entre as telas. A evolução (amadurecimento) do objeto pode ser observada ao longo do decorrer do ciclo de vida do objeto. Como parte do OA "Análise de uma Água Contaminada", a primeira fase é o modelo RIVED do roteiro que é encaminhado à equipe técnica, a seguir, observam-se o núcleo do produto (release zero) e o objeto final, respectivamente.

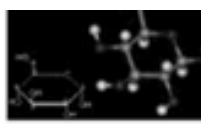

$\rightarrow$ ostigênio (O)

$\rightarrow$ carbono (C)

$\rightarrow$ hidrogênio $(\mathrm{H})$
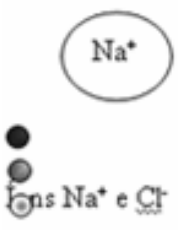

Fons $\mathrm{Na}^{+}$e Clt

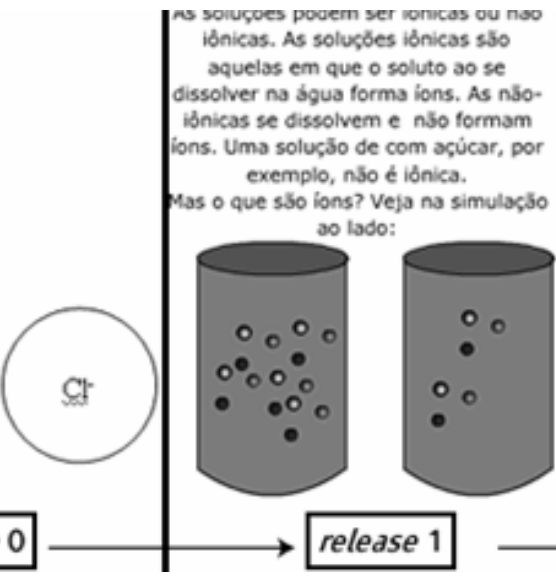

iónicas. As soluxbótes iónicas sabo ma soluç̄o de com açúcar, por

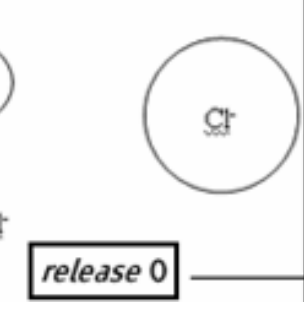

Figura

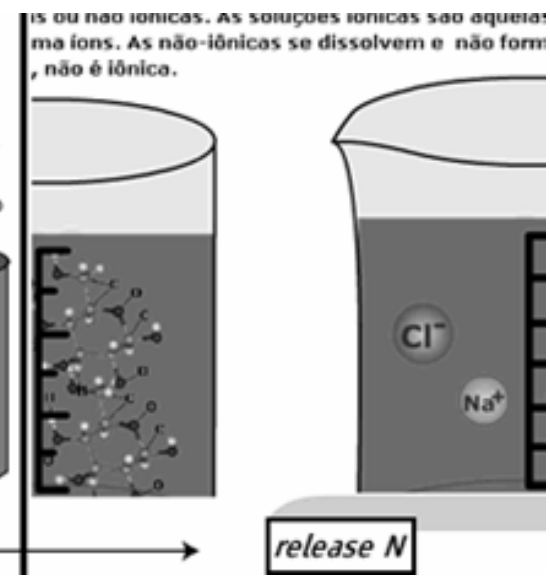

release $N$

Desta forma, consideramos na figura a seguir o aprimoramento do modelo do RIVED (Figura 1) tomando todo o OA como produto. O que antes era apresentado como um fluxograma 
meramente linear, agora incorpora em si ciclos que darão ao OA o amadurecimento e finalidade pretendida.

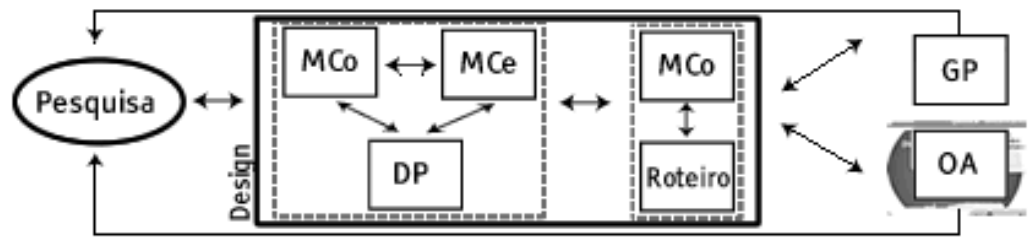

Figura 9. O modelo RIVED com a adoção da proposta de melhoria

\section{Considerações Finais}

Conforme já destacado, o processo de desenvolvimento pode ser mais efetivo se houver registro do projeto do mesmo através de recursos gráficos, que permitam visualização do todo e evitem (ou pelo menos auxiliem) a leitura de material do tipo documento. Este artigo mostrou, aplicado ao caso do projeto RIVED, como mapas conceituais, de cenários e navegacionais podem ser agregados ao processo. Sugerimos a complementação do Design Pedagógico utilizando Mapas Conceituais e de Cenários e do Roteiro utilizando Mapas Navegacionais.

Essas sugestões já foram incorporadas no processo de desenvolvimento de OAs pela equipe da QUIMTIC da UENF no Fábrica Virtual e tem permitido melhoria significativa do processo em termos de tempo e também diminuição dos erros nas etapas intermediárias.

Finalmente, a comunicação entre as equipes através dos mapas conceituais, de cenários e navegacionais tornou as reuniões de projeto mais produtivas, permitindo debatemos sobre uma gama maior de tópicos num menor tempo de duração. O número de releases antes do objeto ser validado junto ao público alvo foi reduzido a metade e a duração das reuniões de projeto foi otimizada em cerca de $50 \%$.

Além das vantagens apontadas quanto ao apoio e melhoria do processo de desenvolvimento, o uso dos três mapas propostos na fase de utilização do OA permite ao professor uma visão clara do escopo abrangido pelo OA, a forma de abordagem do conteúdo via cenários contextualizados e, ainda, conhecer, o processo de navegação.

\section{Referências Bibliográficas}

ABREU, M. F.; CORDEIRO, R. A. C., RAPKIEWICZ, C. E.; CANELA, M. C.;(2006). Utilizando Objetos de Aprendizagem no Processo de Ensino e Aprendizagem de Química no Ensino Médio: o Caso dos Óxidos e da Poluição Atmosférica. In: WIE - XII Workshop de Informática na Escola. Campo Grande - MS.

AMARAL, L. L. do (2006). Um aprimoramento do modelo de processo de criação de objetos de aprendizagem do projeto RIVED. In: WIE - XII Workshop de Informática na Escola. Campo Grande-MS. 
PRESSMAN, R. (2006). Engenharia de Software. $6^{a}$ ed. Editora: McGraw-Hill.

MELO, Ana Cristina (2006). Desenvolvendo aplicações com UML 2.0: do conceitual à implementação. $2^{\mathrm{a}}$ ed. Editora: Brasport.

GILB, T. (1998). Principles of Software Engineering Management. Addison-Wesley.

NASCIMENTO, A e MORGADO, E. (2004). Um projeto de colaboração Internacional na

América Latina. Disponível em <http://rived.proinfo.mec.gov.br/artigos.php> Acessado em: 07/03/2006.

SILVA, R.M.G. e FERNANDES, M.A. (2006) Produção e Desenvolvimento de Objetos de Aprendizagem para o Ensino de Química: Implicações na formação docente. In: XIII Encontro Nacional de Didáticas e Práticas de Ensino. Recife,PE, Anais...

RIVED - Rede Interativa Virtual de Educação. Disponível em: $<$ http://rived.proinfo.mec.gov.br>. Acesso em: 14 de junho de 2007. 